\title{
Determination of the Simultaneously Allowed Optimal Number of Tourists for the Tskaltubo (Prometheus) Cave
}

\author{
Omar Lanchava1,2, Nana Bolashvili³, Akaki Naskhidashvili, Kukuri Tsikarishvili, \\ Zaza Lezhava ${ }^{3}$, Sergo Tsagareishvili ${ }^{4}$, Giorgi Chartolani ${ }^{3 *}$ \\ ${ }^{1}$ G. Tsulukidze Mining Institute, Tbilisi, Georgia \\ ${ }^{2}$ Georgian Technical University, Tbilisi, Georgia \\ ${ }^{3}$ Vakhushti Bagrationi Institute of Geography, Ivane Javakhishvili Tbilisi State University, Tbilisi, Georgia \\ ${ }^{4}$ Akaki Tsereteli State University, Kutaisi, Georgia \\ Email: ^giorgi.chartolani@tsu.ge
}

How to cite this paper: Lanchava, O., Bolashvili, N., Naskhidashvili, A., Tsikarishvili, K., Lezhava, Z., Tsagareishvili, S. and Chartolani, G. (2018) Determination of the Simultaneously Allowed Optimal Number of Tourists for the Tskaltubo (Prometheus) Cave. Open Journal of Geology, 8, 437-445. https://doi.org/10.4236/ojg.2018.84025

Received: February 17, 2018

Accepted: April 24, 2018

Published: April 27, 2018

Copyright $\odot 2018$ by authors and Scientific Research Publishing Inc. This work is licensed under the Creative Commons Attribution International License (CC BY 4.0).

http://creativecommons.org/licenses/by/4.0/

\begin{abstract}
On the southern slope of the Caucasian ridge, the karst strip occupies a 300 $\mathrm{km}^{2}$ of area within the scope of our country, where there are about 1400 caves and shafts registered by these days. Despite the fact that Georgia is sometimes called a country of caves, only a few caves are well-equipped and open for tourists. The research results presented here is based on the conditions of the Tskaltubo cave, which was discovered in 1980s, by speleological team of the Vakhushti Bagrationi Institute of Geography. Cave system is presented with multiple entrances, which has been unknown before for the scientists, located $150 \mathrm{~m}$ above the sea in the Village Kumistavi area, the Tskaltubo Municipality. Over time, due to measures that ensure the safety of visitors as well as heat release from visitors and lighting, the natural background of temperature and relative humidity, the modes of movement of cave air and underground karst waters change. The reason of mentioned for the conditions of Tskaltubo cave is the construction of a special tunnel, which excludes the flooding of the cave during the spring leash season. As a result, the moisture content in the surrounding massif decreases, which also affects the relative humidity and other microclimatic parameters of air. Therefore, the goal of this paper is to reduce the negative impact by determining the optimal number of tourists depending on the season. The method of investigation is based on simple equations of heat balance, in which it is taken into account that all heat, which is released from excursionists and from illumination, is transmitted to cave air. Consequently, taking into account the natural processes of dissipation of thermal energy, the optimal and maximal number of tourists, simultaneously admitted to the cave, is determined. In the paper the table of marked values is given by
\end{abstract}


months of the year. It should be noted that the cave had 80,700 visitors in the first year after the construction of the infrastructure, which exceeds the optimal number of tourists per year about 64,500 according to our research that are presented in this paper.

\section{Keywords}

Cave, Development, Tourism, Monitoring

\section{Introduction}

Achieving the goal-reducing the negative impact of the construction of the drainage tunnel and other infrastructure elements directly requires the presence of natural stationary observations and studies of the early period, when the cave has not yet been exploited. Comprehensive study of the terrain; climatic parameters of the atmosphere and cave air; established modes of natural ventilation, depending on the change in barometric pressure and the corresponding gradient; genesis and regimes of movement of surface, karst and fissured-karst waters; improvement of the existing topographic material of karst caves; compilation of cadastral maps of cave and schemes for their expansion; identification of the characteristics of certain variable parameters of the cave atmosphere: ionization of air, radioactivity, chemical and bacteriological composition of air; hydrometeorological monitoring of the catchment area of the Tskaltubo cave. The scientific papers [1] [2] [3] provide exhaustive information on these factors.

With these objective data in mind, it is advisable to plan the visit of the cave by tourists, so that disturbances caused by visitors and lighting have had minimal impact on the cave microclimat, on the physical characteristics of the surrounding massif, on the regimes of the movement of cave air and karst waters. Consequently, the set goal can be fulfilled by predicting seasonal fluctuations of the noted physical quantities, changing the characteristic indices of physical fields depending on the attendance of the cave, monitoring the noted physical quantities in the long term, and observing the dynamics of the proceeding processes.

The developed touristic object of Tskaltubo-the cave of Prometheus is situated at a distance of $255 \mathrm{~km}$ from Tbilisi, $100 \mathrm{~km}$ from Black Sea port Poti, 16 $\mathrm{km}$ from Kutaisi and $6 \mathrm{~km}$ from the resort Tskaltubo on the main touristic route.

\section{Methods of Research}

Paying due attention to the law of conservation of energy, on the basis of simple heat balance equations, we believe that the heat emitted by people and lighting is completely transferred to cave air, which from its part sends the received heat to the walls of the cave and surrounding massif. Consequently, taking into account the natural processes of dissipation of thermal energy, the optimal number of tourists admitted simultaneously into the cave is determined. From the point of 
view of the recoupment of expenses for construction and security work in the cave, the maximum number of tourists is determined according to the principle of sufficiency of the ventilation air of the cave for the life of people. Thus, the maximum number of tourists is determined from the sufficiency of air for breathing, and the optimum quantity is determined from the point of view of the dissipation of the released heat in the environment.

It should be noted that according to the results of the research presented in this paper, the cave Tskaltubo (Prometheus) refers to the so-called elite caves, in which a relatively small number of people are admitted simultaneously. Proceeding from the principle of restoring disturbed physical fields, the cave can only be open for 8 hours a day. The remaining time during the day (24-hour period) is required to naturally neutralize the disturbance of heat and moisture fields induced by means of people and lighting in the cave.

Based on the proposed methods of research, thermophysical calculations are based on the following data:

1) the number of well-equipped halls (viewing platforms) in which a group of tourists stops and inspects the hall. Lighting should be included in the hall in time-15;

2) total power of lighting in one hall $-5 \mathrm{~kW}$;

3) total power of additional lighting along the entire path near $910 \mathrm{~m} \mathrm{(100} \mathrm{W}$ for every $22-23 \mathrm{~m})-4 \mathrm{~kW}$;

4) the length of the part of the cave where tourists are allowed-910 m;

5) the speed of the tourists $-0.7 \mathrm{~km} / \mathrm{h}$.

For the purposes of thermophysical calculations, the route of the cave movement was divided into 4 zones with a length of 260, 270, 170 and $210 \mathrm{~m}$ and 910 $\mathrm{m}$ in total [2].

\section{Discussion}

The stationary and semi-stationary meteorological observations conducted over a number of years in the cave system reveal that [2] [3] [4]:

The mode of annual variation of atmospheric pressure in the cave system and on the surface determines the conditions for air circulation in the underground cavity. It is established that the reason for the movement of air apart from changes in atmospheric pressure is also the airs density increments, depending on the place of observation. The daily fluctuation of atmospheric pressure has one maximum and one minimum within 24 hours. The time of peak indicators of extreme values varies depending on the morphology of the cavity and the height of the observation point.

The general feature characteristic to Tskaltubo cave climate is quick decrease of the air temperature (approximately $0.15-0.20$ ) and the absolute humidity (approximately $0.08-0.10$ ) variation coefficients from the entrance to the depth of the cave.

Figure 1 shows the dynamics of temperature changes in cave air along the 
length of the excursion route, and in Figure 2, the daily fluctuation of cave air in the halls of the cave.

The annual traffic of the air temperature is characterized by insignificant changes. At the height of $20-50 \mathrm{~cm}$ from the cave floor, the air temperature is relatively lower $(0.5-0.9)$ than at the height of $1.5-2.0 \mathrm{~m}$. Based on this, it is clear that the air speed is less than critically $(0.10-0.15 \mathrm{~m} / \mathrm{sec})$ according to Reynolds. Therefore, the air flow is not turbulent and takes place layering of air flow by the temperature. At a distance from the cave entrance this difference disappears and a relatively stable climatic zone presents itself, in which the 24-hour amplitude of the air temperature is almost absent. In some zones of cave

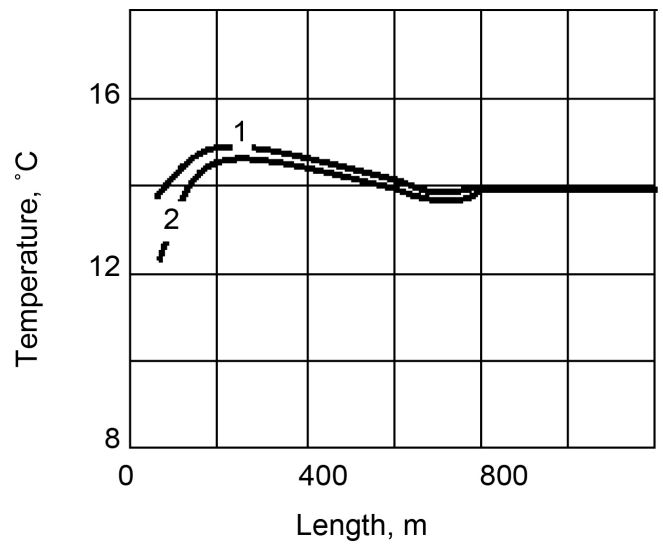

Figure 1. The dynamics of temperature changes in cave air along the length of the excursion route.

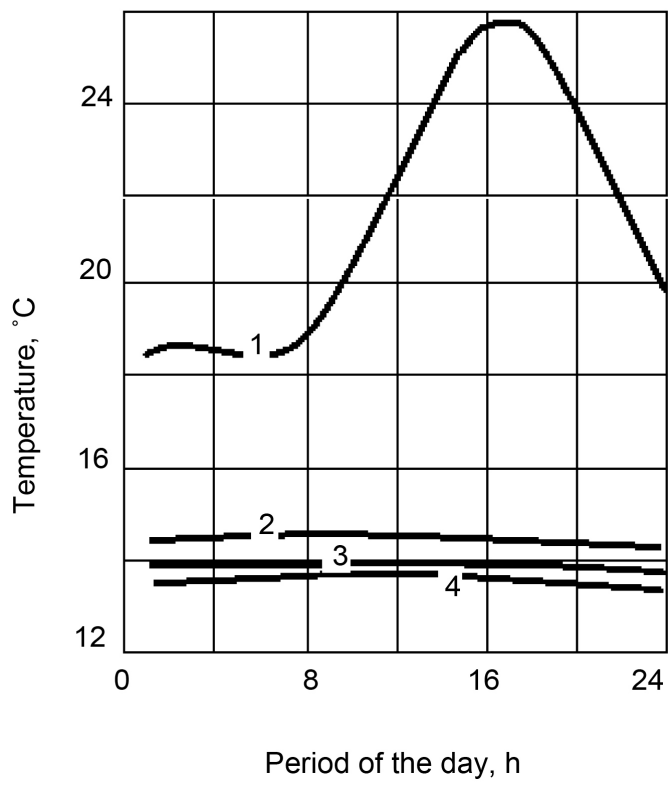

Figure 2. The daily oscillation of temperature of cave air on the surface and in the halls of the cave: 1-surface; 2-Kutaisi Hall; 3-Hall of climbers; 4 -at place of underground beach. 
path for visitors, especially in the area of siphon lakes and moving water currents the 24-hour amplitude changes within the range of $0.1-0.3$.

The temperature of surrounding rock massif is equal to the neutral layer temperature of these locations $\left(13^{\circ} \mathrm{C}-14^{\circ} \mathrm{C}\right)$ and does not actually change during the year. Because of this, when the average temperature of atmospheric air exceeds the neutral layer temperature and the air's absolute humidity is high in nature and due to air cooling, in the places where the underground space is connected to the atmosphere takes place a local condensation of moisture. The air quantitively drains, because the absolute humidity decreases, but is qualitatively moistened due to the increase in relative humidity. Because the air flow speed is low, i.e. the same thing as air expenses is relatively small, the condensation area is spread within $50-80 \mathrm{~m}$ from of mentioned places. In this case the heat of the "liquid-vapor" phase transition is transferred to both components of the thermodynamic system "surrounding massif-cave air".

Figure 3 shows the dynamics of daily fluctuation of cave airs relative humidity and on a surface.

In the winter occurs the evaporation from the open surface of the mining array and cave formations, and at this time the heat of steam or enthalpy of phase transformation "liquid-vapor" is completely absorbed from massif and the air is heated. The air is quantitatively moistened, but since the rate of temperature increase is greater than the rate of increase in the moisture content of air, due to the different rates of growth of these physical quantities, in fact, the numerical value of the relative humidity decreases.

In according of ASHRAE handbook-fundamentals in relatively calm state, when the ambient temperature is 14 (18) 0C, a person emits approximately 118 (104) J heat per hour [5]. The amount of the heat emitted by people inside the cave is calculated by the formula [6]

$$
Q_{1}=105 n \tau_{1} m
$$

where $Q_{1}$-the amount of heat emitted by people, J/h;

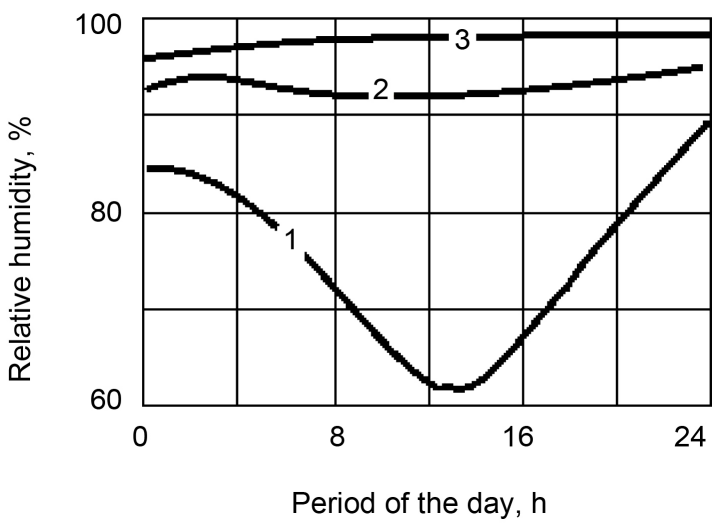

Figure 3. The daily oscillation of relative humidity of cave air on the surface and in the cave: 1-surface; 2entrance; 3 -at place of underground beach. 
$n=50$ - the number of excursionists in one group;

$\tau_{2}=1.3 \mathrm{~h}$-time of passing of an excursion way in length of $910 \mathrm{~m}$ with speed of movement of $0.7 \mathrm{~km} / \mathrm{h}$;

$m$-the number of groups of excursionists during a day; $m=6$ in the 8 -hour regime of the cave exploitation.

The amount of the heat emitted by the lighting is calculated as per the formula [6]

$$
Q_{2}=N \tau_{2},
$$

where $Q_{2}$-the total amount of heat emitted by the lighting along the tunnel route and on viewing platforms arranged along the excursion route, $\mathrm{J} / \mathrm{h}$;

$N$-the network-derived power of lighting, W;

$\tau_{2}$ - the time of lighting turning on, $h$.

For the main traffic route, it is accepted that $\tau_{2}=\tau_{1}$, whereas for individual halls $\tau_{2}=0.067 \mathrm{~h}$. For the excursion route $N=4000 \mathrm{~W}$; for each viewing platforms $N=5000 \mathrm{~W}$. For the same main traffic route, it is accepted that $\tau_{2}=\tau_{1}$, whereas for individual halls $\tau_{2}=0.067 \mathrm{~h}$. For 4 zones of 260, 270, 170 and 210 $\mathrm{m}$ in length, the viewing areas are distributed in numbers as follows $4,4,3,4$. For the excursion route $N=4000 \mathrm{~W}$; for each viewing platforms $N=5000 \mathrm{~W}$.

According to formula (2), it is assumed that all the power that is necessary for the light turns into heat and takes place its subsequent dissipation into the underground space. The results of the released heat indexes in figures obtained from the thermophysical calculations are entered into Table 1 according to the areas of calculation.

The depressive planning performed in Tskaltubo (Prometheus) cave revealed aerodynamic connection of the underground space with the surface. The cave is mainly aerated with natural traction, although in certain individual periods the air exchange gets greatly influenced by dynamic factors. The amount of the air incoming into the cave during the different periods/seasons of the year (23 $\mathrm{m}^{3} / \mathrm{min}$-April; $58 \mathrm{~m}^{3} / \mathrm{min}$-August) and their direction varies in a short period of time.

In general, only hygroscopic moisture exchange takes place here after the construction of a tunnel to eliminate the tunnel flooding. Before that a flooding occurred periodically during spring floods and the surrounding rock massif and tunnel formations were moistened in contact with water. Therefore, the relative humidity of the equilibrium air was high and was equal $100 \%$. Due to the construction of the tunnel, the content of moisture of surrounding tunnel massif

Table 1. Heat Emission in Tskaltubo (Prometheus) Cave by results of exploitation.

\begin{tabular}{cccccccc}
\hline No. & $\tau_{1}, \mathrm{~h}$ & $m$ & $n$ & $\tau_{2}, \mathrm{~h}$ & $Q_{1}, \mathrm{~J} / \mathrm{h}$ & $Q_{2}, \mathrm{~J} / \mathrm{h}$ & $\Sigma Q, \mathrm{~J} / \mathrm{h}$ \\
\hline 1 & 0.37 & 6 & 50 & 0.268 & 11,655 & 2420 & 14,075 \\
2 & 0.39 & 6 & 50 & 0.268 & 12,285 & 2900 & 15,185 \\
3 & 0.24 & 6 & 50 & 0.201 & 7560 & 1965 & 9525 \\
4 & 0.30 & 6 & 50 & 0.268 & 9450 & 2540 & 11,990 \\
\hline
\end{tabular}


is naturally drained and the equilibrium relative humidity is only $95 \%-96 \%$ [6].

The thermophysical calculations enabled us to identify the optimal and maximal numbers of the people to be allowed into the cave at the same time; these numbers are presented hereby in Table 2 broken down according to the months.

Table 3 provides the number of potential sightseers allowable into Tskaltubo (Prometheus) cave over a year according to the months.

In the result of thermal physical calculations, it was identified that the highest temperature in winter conditions is expected at the end of the 4th zone of pathin the area in which the source of karst gets lost in the siphon, whereas in summer maximal temperature is expected on the opposite side-in the halls situated by the entrance to the cave. When operating the cave according to the results that are presented in the tables, at the end of 8 hours of operation, the air

Table 2. The number of people allowable into Tskaltubo (Prometheus) cave at the same time.

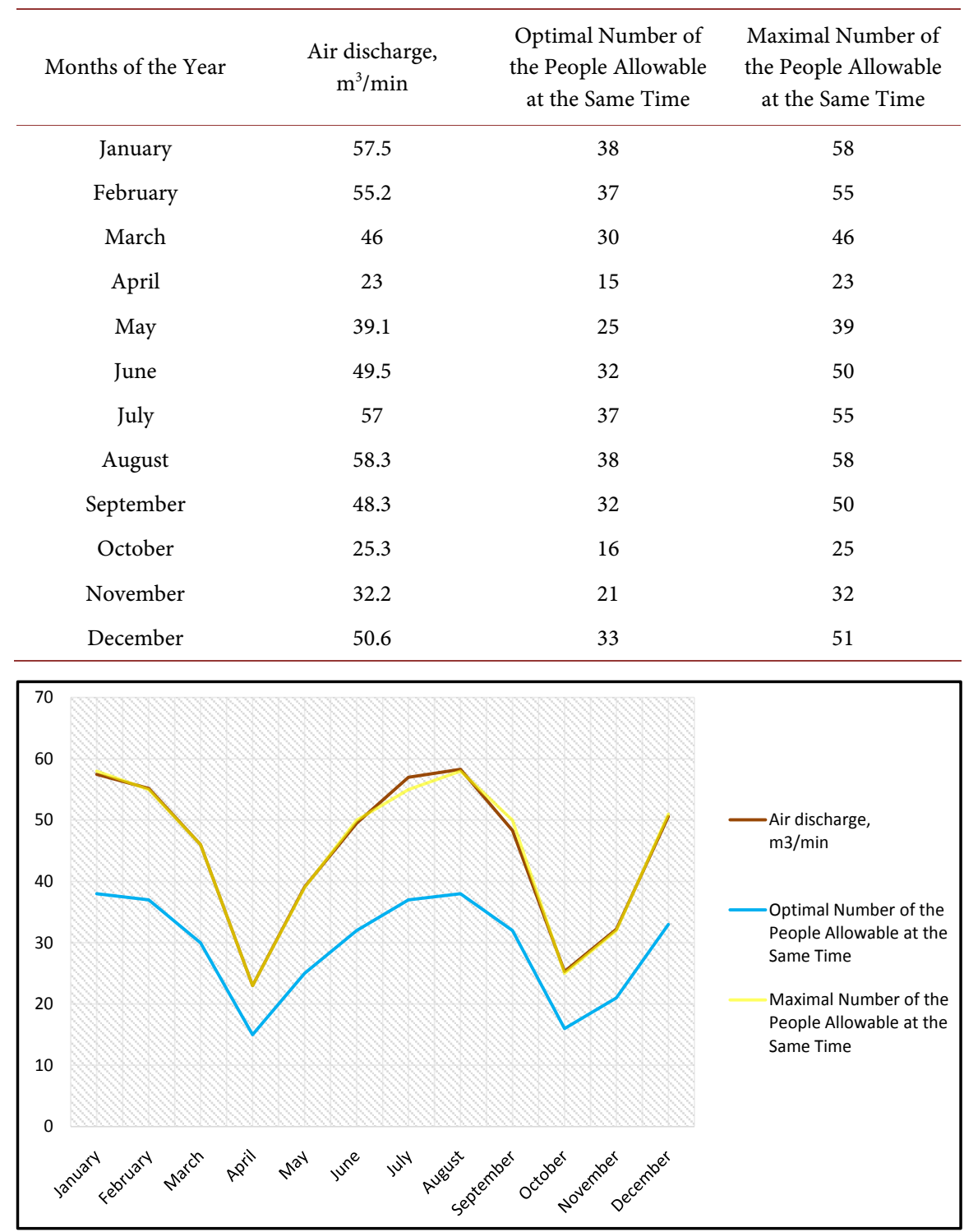


Table 3. The number of potential sightseers allowable into Tskaltubo (Prometheus) cave over a year according to the months.

\begin{tabular}{ccc}
\hline Months of the Year & $\begin{array}{c}\text { Optimal Number of } \\
\text { Sightseers According to } \\
\text { Months }\end{array}$ & $\begin{array}{c}\text { Maximal Number of } \\
\text { Sightseers According to } \\
\text { Months }\end{array}$ \\
\hline January & 6216 & 10,788 \\
February & 5580 & 9240 \\
March & 2700 & 8556 \\
April & 4500 & 4278 \\
May & 5760 & 7020 \\
June & 6882 & 9000 \\
July & 7068 & 10,230 \\
August & 5760 & 10,788 \\
September & 2976 & 9000 \\
October & 3780 & 4650 \\
November & 6138 & 5760 \\
December & 64,428 & 9486 \\
Total annual & & 98,796 \\
\hline
\end{tabular}

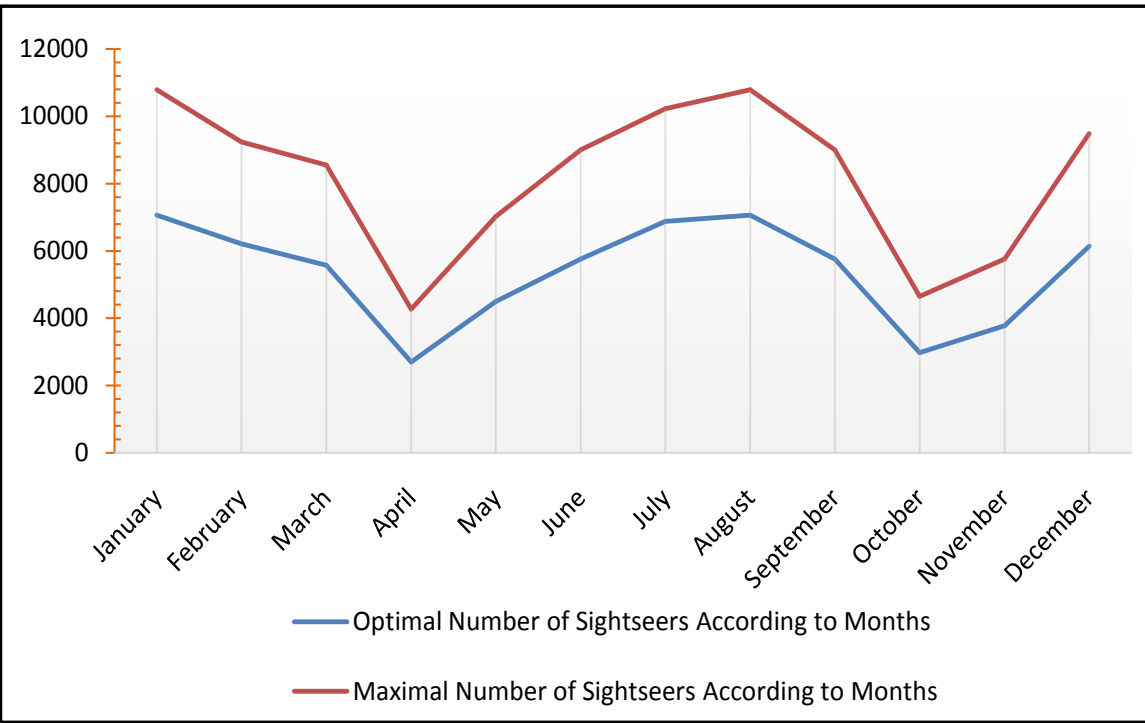

temperature rises by $4.5^{\circ} \mathrm{C}-5.0^{\circ} \mathrm{C}$ along the entire length of the route of the excursion. The noted increment is partially removed during the rest of the day, but there is still an elevated temperature background in the amount of $0.2^{\circ} \mathrm{C}-0.4^{\circ} \mathrm{C}$ during a month. After a long operation of the cave, its temperature regime will change thoroughly, because nature alone cannot neutralize the marked outrage.

As for the other indicator of climatic parameters-relative humidity, it decreases steadily during the operation of the cave. The reason for this is, on the one hand, the marked increase in air temperature, and on the other hand, and to a greater extent, the construction of a drainage tunnel, which causes a general drying of the underground cavity. In this regard, the issue of maintaining the 
moisture content of the surrounding massif and cave formations and regulating of humidity of underground air requires special individual studies and efforts [4].

It should also be mentioned here that in order to maintain the natural climatic regime of the cave, we see that is necessary: 1) exploitation of cave in according the new results of researches; 2) establishing and exercising of systematic control over an optimal variant of the cave system utilization; 3) permanent measurements of temperature, relative humidity and air speed and comparison of these parameters with field observations performed before the beginning of operation of the cave; 4) removing of perturbations of temperature and relative humidity of cave air, as well as corresponding physical fields of temperature and moisture content of the surrounding massif.

\section{Conclusions}

Based on the results of this paper, we can draw the following conclusions:

- exploitation of the cave for tourist purposes causes disturbances in the natural temperature and moisture content of the surrounding massif and the corresponding climatic parameters of cave air;

- to minimize the noted disturbances in the cave, it is necessary to allow an optimal number of tourists in the underground space for excursion depending on the season;

- it is necessary to carry out $\ni$ permanent monitoring over changing the parameters of physical fields and by comparing them with the basic data of field observations, making corrections to the results presented here in order to preserve the unique natural wealth.

\section{References}

[1] Gigineishvili, G., Tatashidze, Z. and Tsikarishvili, K. (2007) Geography-Hydrological Arguments on Possible Expansion of the Tskaltubo Cave System. Bulletin of the Georgian National Academy of Sciences, 175, 67-70.

[2] Lanchava, O. and Tsikarishvili, K. (2014) On the Necessity to Monitor The Equipped Karst Caves with a View to Optimal Operation (Illustrated by New Athos and Tskhaltubo Caves in Georgia). International Research-to-Practice Conference on Integrated Use and Protection of Underground Spaces, devoted to the 100th Anniversary of Scientific and Tourist-Excursion Activities in Kungur Ice Cave and V.S. Liukin's 100th Birthday Anniversary, Perm, 40-41.

[3] Jishkariani, J., Tatashidze, Z., Tsiqarishvili, K. and lanchava, O. (2010) Main Results of Complex Research into the Tskaltubo Cave System. Bulletin of the Georgian National Academy of Sciences, 4, 92-95.

[4] Bolashvili, N., Lanchava, O. and Tsikarishvili, K. (2017) Tskhaltubo (Prometheus) Cave System. Lap. Lambert Academic Publishing, Saarbrucken, 136.

[5] https://www.ashrae.org/File\%20Library/Technical\%20Resources/ASHRAE\%20Han dbook/I-P_F2017-IndexIX.pdf

[6] Lanchava, O. (2005) Separation and Evaluation of Simultaneous Heat-Mass Exchange in Binary Systems. Bulletin of the Georgian National Academy of Sciences, 172, 400-403. 